\title{
Anabaena sp. strain PCC 7120 conR contains a LytR-CpsA-Psr domain, is developmentally regulated, and is essential for diazotrophic growth and heterocyst morphogenesis
}

Correspondence

James W. Golden

jwgolden@ucsd.edu

Received 13 October 2010

Revised 16 November 2010

Accepted 17 November 2010

\author{
Rodrigo A. Mella-Herrera, ${ }^{1,2}$ M. Ramona Neunuebel ${ }^{1} \dagger$ and \\ James W. Golden ${ }^{2}$ \\ ${ }^{1}$ Department of Biology, Texas A\&M University, College Station, TX 77843-3258, USA \\ ${ }^{2}$ Division of Biological Sciences, University of California San Diego, La Jolla, CA 92093-0116, USA
}

The conR (all0187) gene of the filamentous cyanobacterium Anabaena (Nostoc) sp. strain PCC 7120 is predicted to be part of a family of proteins that contain the LytR-CpsA-Psr domain associated with septum formation and cell wall maintenance. The conR gene was originally misannotated as a transcription regulator. Northern RNA blot analysis showed that conR expression was upregulated $8 \mathrm{~h}$ after nitrogen step-down. Fluorescence microscopy of a $\mathrm{P}_{\text {conR }}$-gfp reporter strain revealed increased GFP fluorescence in proheterocysts and heterocysts beginning $9 \mathrm{~h}$ after nitrogen step-down. Insertional inactivation of conR caused a septumformation defect of vegetative cells grown in nitrate-containing medium. In nitrate-free medium, mutant filaments formed abnormally long heterocysts and were defective for diazotrophic growth Septum formation between heterocysts and adjacent vegetative cells was abnormal, often with one or both poles of the heterocysts appearing partially open. In a conR mutant, expression of nifH was delayed after nitrogen step-down and nitrogenase activity was approximately $70 \%$ of wildtype activity, indicating that heterocysts of the conR mutant strain are partially functional. We hypothesize that the diazotrophic growth defect is caused by an inability of the heterocysts to transport fixed nitrogen to the neighbouring vegetative cells.

\section{INTRODUCTION}

The filamentous cyanobacterium Anabaena (also Nostoc) sp. strain PCC 7120 (hereafter Anabaena PCC 7120) is capable of fixing carbon dioxide by oxygenic photosynthesis and fixing molecular nitrogen when a combined nitrogen source such as ammonium or nitrate is not available. These two processes are incompatible because nitrogenase is oxygen-sensitive and oxygen is produced as a by-product of photosynthesis. Anabaena PCC 7120 spatially separates these processes by undergoing multicellular development in which $5-10 \%$ of vegetative cells differentiate into specialized cells called heterocysts, which switch from photosynthesis to nitrogen fixation and supply the filament with fixed nitrogen as amino acids (Aldea et al., 2008; Flores \& Herrero, 2010; Kumar et al., 2010).

Heterocyst differentiation involves morphological and physiological changes that produce the micro-oxic envi-

tPresent address: Cell Biology and Metabolism Program, Eunice Kennedy Shriver National Institute of Child Health and Human Development, Bethesda, MD 20892, USA.

Abbreviation: DIC, differential interference contrast [microscopy]. ronment necessary for nitrogen fixation (Flores \& Herrero, 2010; Kumar et al., 2010). This micro-oxic environment is generated by the inactivation of the oxygen-producing photosystem II, an increase in respiration and the deposition of a multilayered cell envelope consisting of an inner layer of glycolipids and an outer layer of polysaccharides that diminishes $\mathrm{O}_{2}$ entry into the cell. Heterocysts are present in a developmental pattern of single heterocysts separated by $10-15$ vegetative cells that is regulated by cell-cell signalling involving the products of the pat $S$ and het $N$ genes, as well as fixed nitrogen produced by heterocysts (Borthakur et al., 2005; Kumar et al., 2010; Risser \& Callahan, 2009; Yoon \& Golden, 1998, 2001; Zhang et al., 2006). Heterocysts supply vegetative cells with fixed nitrogen, and vegetative cells supply fixed carbon to the heterocysts (Popa et al., 2007). Transport of metabolites between cells along each filament appears to involve both cytoplasmic connections between adjacent cells and possibly a continuous periplasm (Flores \& Herrero, 2010; Mariscal et al., 2007; Mullineaux et al., 2008; Zhang et al., 2008).

The early stages of heterocyst differentiation require increased levels of the regulators NtcA and HetR, which 
are mutually dependent on each other for upregulation (Muro-Pastor et al., 2002). NtcA is an autoregulatory transcription factor that belongs to the cAMP receptor protein (CRP) family (Herrero et al., 2004). HetR has DNA-binding activity that is inhibited in vitro by a synthetic pentapeptide corresponding to the C-terminal region of the PatS product (Huang et al., 2004). As cells undergo heterocyst differentiation they reach a point at which the regulation becomes irreversible. For Anabaena PCC 7120, proheterocysts become committed to complete differentiation between 9 and $13 \mathrm{~h}$ after nitrogen stepdown (Yoon \& Golden, 2001).

During maturation, a polysaccharide layer is deposited around the proheterocyst followed by the deposition of a glycolipid layer between the outer membrane and the polysaccharide layer. Synthesis and deposition of the heterocyst envelope polysaccharide (Hep) layer requires a cluster of genes that includes hepA and hepC, and other genes outside of the cluster including hepB, alr3699 and all4160; expression of these genes is upregulated early during heterocyst differentiation 5-8 h after induction (Huang et al., 2005; Wang et al., 2007). Several genes with regulatory roles have been shown to be required for regulation of the hep genes, including hepK and $\operatorname{dev} R$, which form a two-component system: henR (response regulator), hepN (histidine kinase) and hepS (serine/ threonine kinase) (Lechno-Yossef et al., 2006).

Synthesis of the heterocyst glycolipid ( $\mathrm{Hgl})$ layer requires a cluster of $h g l$ genes, and $\operatorname{devBCA}$ and $h g l K$, which are required for transport and assembly (Awai et al., 2009; Fan et al., 2005; Muro-Pastor et al., 2009). Mutations that compromise the integrity of the polysaccharide or the glycolipid layer cause a Fox ${ }^{-}$phenotype characterized by the inability of the heterocysts to perform nitrogen fixation in the presence of oxygen.

Fan et al. (2006) previously identified gene allo187, the subject of this paper, in a transposon mutagenesis screen for mutants with a Fox ${ }^{-}$phenotype. They named the gene conR for constriction regulator; however, the annotation as a transcriptional regulator was erroneous (see Results). The conR transposon mutant was unable to grow diazotrophically. Although the polysaccharide and glycolipid envelope layers were present in the mutant, the polar junctions connecting heterocysts to vegetative cells were incomplete or widely open, which they hypothesized would allow oxygen to enter the heterocysts and inactivate nitrogenase (Fan et al., 2006).

Here, we report our independent identification of the Anabaena PCC 7120 conR gene and additional characterization of its expression and function.

\section{METHODS}

Strains and culture conditions. Strains and plasmids used in this study are listed in Table 1. Anabaena PCC 7120 and its derivatives were typically grown in $100 \mathrm{ml}$ BG-11 or BG-11 $1_{0}$ (lacking sodium nitrate) medium in $250 \mathrm{ml}$ flasks at $30{ }^{\circ} \mathrm{C}$ with white-light illumination of approximately $75 \mu \mathrm{mol}$ photons $\mathrm{m}^{-2} \mathrm{~s}^{-1}$ as described previously (Wu et al., 2007). Plates contained $40 \mathrm{ml}$ medium solidified with $1.5 \%$ agar; for BG- $11_{0}$ plates, the agar was washed (Waterbury \& Willey, 1988) to remove trace nitrogen compounds. For media containing ammonium, ammonium chloride $(2.5 \mathrm{mM})$ and MOPS buffer $(5 \mathrm{mM}, \mathrm{pH} 8.0)$ were added to BG-11 . For Anabaena PCC 7120 strains containing shuttle or suicide plasmids grown on solid medium, antibiotics were used at the following concentrations: neomycin $25 \mu \mathrm{g} \mathrm{ml}{ }^{-1}$, or spectinomycin and streptomycin $2 \mu \mathrm{g} \mathrm{ml}^{-1}$ each; for liquid medium these concentrations were reduced by half. Escherichia coli strains were grown in LB (Lennox L) medium containing appropriate antibiotics at $37^{\circ}$ C. E. coli strain DH10B was used for all cloning experiments.

Suicide and shuttle plasmids were transferred to E. coli donor strain AM1359 by electroporation and transferred to Anabaena PCC 7120 strains by conjugation using standard protocols (Elhai et al., 1997) with minor modifications (Khudyakov \& Golden, 2001). For cyanobacterial genetics experiments, the phenotype of several independent exconjugant clones was determined to check for consistency. To obtain segregated gene knockouts by single recombination with a suicide plasmid containing an internal fragment of the gene, at least six original exconjugant colonies were restreaked three times onto fresh BG-11 antibiotic plates and then grown in liquid BG-11 with antibiotic before inducing heterocyst development by nitrogen step-down.

Bioinformatics. Standard bioinformatics analyses were performed with web-based software including CyanoBase, UniProtKB and Pfam.

Plasmid constructions. Standard protocols were used for cloning and E. coli transformation. Total DNA from cyanobacterial strains was isolated as described previously (Khudyakov \& Golden, 2001). DNA sequencing of plasmid inserts was performed by the Gene Technologies Laboratory (Texas A\&M University) following the Big Dye sequencing protocol (Applied Biosystems). All plasmid constructions were verified by DNA sequence analysis.

All primers used in this study are listed in Table 2. The open reading frame conR was inactivated by single homologous recombination with suicide plasmid pAM3438, which contained an internal fragment of conR amplified by PCR using oligonucleotides AMO903 and AMO-904. The amplified fragment was digested with XhoI and SacI and inserted into the corresponding sites of the suicide plasmid pRL277. Recombination of the suicide plasmid into the $\operatorname{conR}$ gene and the absence of wild-type copies of the gene were confirmed by PCR and Southern blot analysis for three exconjugants (data not shown).

Plasmid pAM3348 was constructed for overexpression of conR from the Anabaena PCC $7120 \mathrm{rbcL}$ promoter. This plasmid contains the conR gene, including $37 \mathrm{bp}$ upstream and $2 \mathrm{bp}$ downstream of the ORF, on a PCR fragment generated with primers AMO-955, which contains an engineered ClaI site, and AMO-956, which contains an engineered SalI site. The PCR product was digested with ClaI and SalI and cloned into the same sites of pAM1824.

To construct a shuttle plasmid carrying a $\mathrm{P}_{c o n R^{-}} g f p$ transcriptional fusion, a fragment extending from $402 \mathrm{bp}$ upstream to $63 \mathrm{bp}$ downstream of the conR translational start site was amplified by PCR with primers AMO-959 and AMO-960. The fragment was digested with SmaI and $\mathrm{XbaI}$ and cloned into pBluescript SK+ digested with EcoRV and XbaI to produce pAM3451. A SalI-SacI fragment containing the insert was excised from pAM3451 and ligated into the same sites of pAM1956, a shuttle plasmid containing the promoterless gfpmut2 gene, producing pAM3450. 
Table 1. Bacterial strains and plasmids

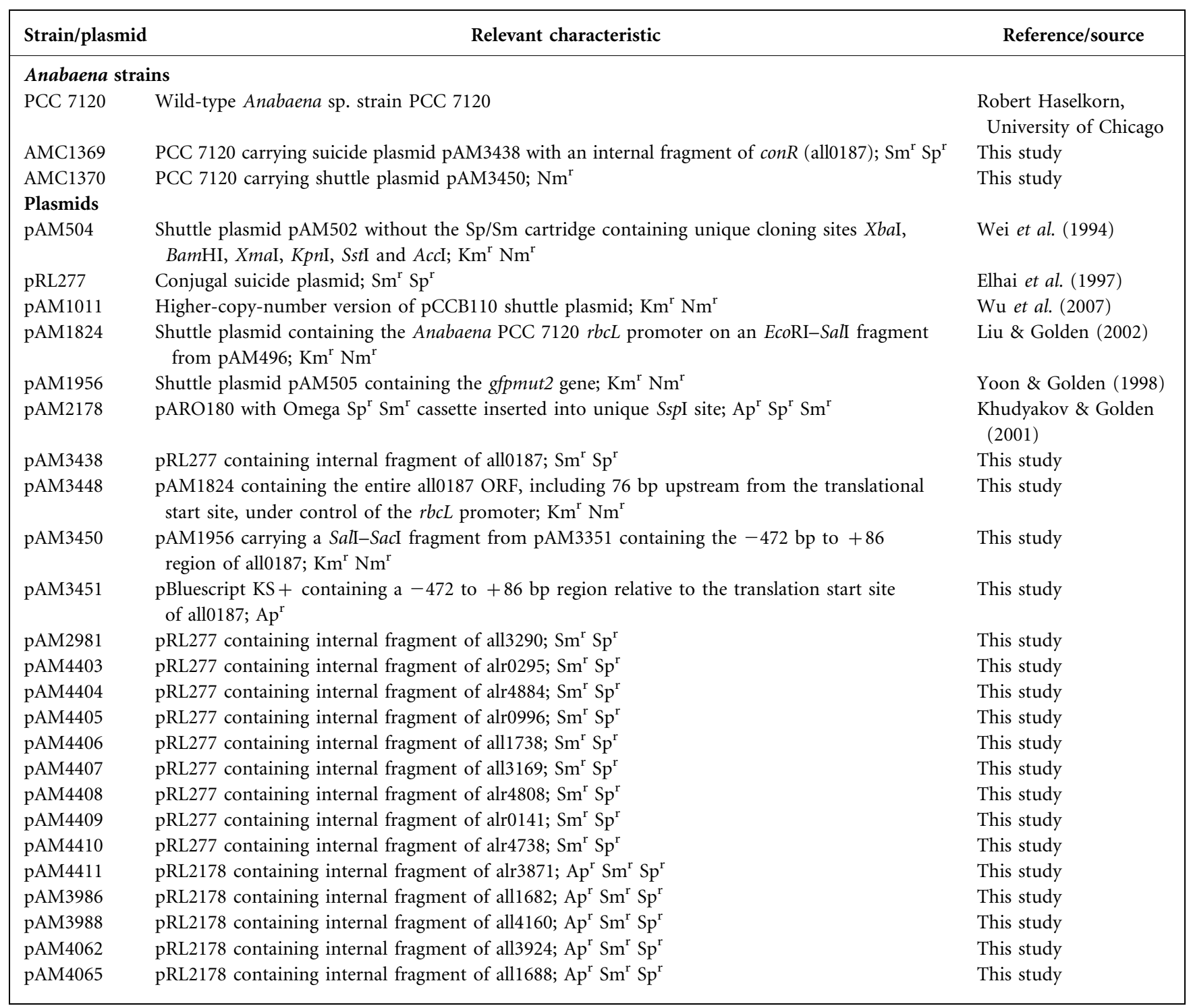

RNA isolation. Total RNA was extracted using the RiboPureBacteria kit (Ambion) according to the manufacturer's instructions. For synchronous induction of heterocyst development by nitrogen step-down, Anabaena PCC 7120 filaments from a dark-green BG-11 culture were inoculated into $100 \mathrm{ml} \mathrm{BG-11_{0 }}$ supplemented with $2.5 \mathrm{mM}$ ammonium chloride and $5 \mathrm{mM}$ MOPS ( $\mathrm{pH}$ 8.0) to obtain a starting $\mathrm{OD}_{750}$ of $0.025-0.035$. The cells were grown overnight until $\mathrm{OD}_{750}$ reached $0.05-0.075$, after which they were collected by centrifugation, washed twice with sterile water and then transferred

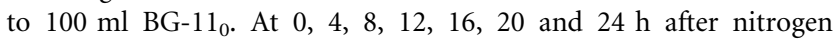
deprivation, $100 \mathrm{ml}$ cultures were poured into a conical $250 \mathrm{ml}$ centrifuge tube containing $100 \mathrm{~g}$ ice to rapidly stop mRNA synthesis and degradation, and the filaments were collected by centrifugation at $5000 \mathrm{~g}$ for $10 \mathrm{~min}$ at $4{ }^{\circ} \mathrm{C}$. The cell pellet was immediately frozen at $-80{ }^{\circ} \mathrm{C}$ for storage until RNA extraction was performed.

Northern RNA blot analysis. Five micrograms of total RNA for each sample was denatured and run on a $1 \%$ agarose denaturing formaldehyde gel in MOPS buffer and transferred to a MAGNACHARGE nylon membrane (GE Water \& Process Technologies) with $10 \times$ SSPE (Golden et al., 1991; Sambrook \& Russell,
2006). Blots were hybridized with radioactively labelled DNA probes. Probe fragments were amplified by PCR using the corresponding primers (Table 2), labelled with $\left[{ }^{32} \mathrm{P}\right]$-dCTP by random primer labelling, and purified on Micro Bio-Spin P-30 columns (Bio-Rad). The hybridization solution contained $5 \times$ SSPE, $50 \%$ formamide, $0.5 \%$ SDS and $5 \times$ Denhardt's solution, and hybridization was performed overnight at $42{ }^{\circ} \mathrm{C}$. Blots were washed twice for $5 \mathrm{~min}$ with $2 \times \mathrm{SSC} / 0.1 \% \mathrm{SDS}$ at room temperature, once for $10 \mathrm{~min}$ with $1 \times \mathrm{SSC} / 0.1 \% \mathrm{SDS}$ at $65{ }^{\circ} \mathrm{C}$, and once for $10 \mathrm{~min}$ with $0.5 \times \mathrm{SSC} /$ $0.1 \%$ SDS at $65{ }^{\circ} \mathrm{C}$. Blots were exposed on a phosphorimager plate and scanned with a Phosphorimager BAS-5000 (Fujifilm).

Microarray experiments. Labelled Anabaena PCC 7120 RNA samples were hybridized to a custom microarray slide manufactured by Integrated Genomics. Each slide contained probes for 768 ORFs from the Anabaena PCC 7120 genome, including heterocyst-related genes, regulatory genes, photosynthesis genes, clock genes and selected additional genes. The array included six duplicates of each gene, 96 negative controls (repeated six times each) and 11 positive controls (repeated 48-196 times). In total, each slide contained 5760 spots; 50 probes were 70 -base oligonucleotides and the remainder 
Table 2. Primers used in this study

\begin{tabular}{|c|c|c|c|c|}
\hline \multirow[t]{2}{*}{ Gene } & \multicolumn{2}{|r|}{ Forward primer } & \multicolumn{2}{|r|}{ Reverse primer } \\
\hline & Name & Sequence $\left(5^{\prime} \rightarrow 3^{\prime}\right)$ & Name & Sequence $\left(5^{\prime} \rightarrow 3^{\prime}\right)$ \\
\hline all0187-internal & AMO-903 & CTCGAGTGTTTCCCGTAACGTGGTTG & AMO-904 & GAGCTCAAACTCACCCTAGAGCGACG \\
\hline all0187-ORF & AMO-955 & GCTTGATCGATCATAAATTTTAGGGAG & AMO-956 & CCACTGTCGACTAACTATTTCCAATC \\
\hline $\mathrm{P}_{\text {conR }}-g f p$ & AMO-959 & GGCCCCGGGCGTGCTTCTACCCTG & AMO-960 & CACCTCTAGATTGAGATCCGGTATTTG \\
\hline all0185 & AMO-1032 & GCCCAGATTTTCTTGGCAG & AMO-1033 & CATGGGCTGCATTGACAC \\
\hline all0186 & AMO-1005 & GTTATGCTGGCGTGG & AMO-1006 & CAATACCCGTAACTC \\
\hline alr0188 & AMO-1007 & GACTGGTTAAGTTCG & AMO-1008 & GACTGGTTAAGTTCG \\
\hline$r n p B$ & AMO-489 & GTACTGCGGGTAACTAAAG & AMO-490 & AATGACTATTGACTAAAAG \\
\hline nifH (all1445) & AMO-622 & TTCACGGTCAACCTTACGG & AMO-1038 & CGGTAAAGGCGG \\
\hline hcwA (alr0093) & AMO-1549 & CAGTGCTGCACCCGG & AMO- 1550 & GTTCCTGGTTGGGGT \\
\hline all3290 & AMO-659 & AACCAACATATG GTGATTCGTCCTTGTAAACC & AMO-660 & AACCAACCCGGGTCATGGCTTGACTACCTCC \\
\hline alr0295 & AMO-886 & CAAGGCTCGAGAGAAACTGCTGTAG & AMO-887 & GACCTGAGCTCAAAAACAGCAGAGTATC \\
\hline alr4882 & AMO-888 & CTTCAGCTCGAGCAGGATAAAATGTCTGC & AMO-889 & ACAATAGAGCTCTGAGCGATCGCTAACCC \\
\hline alr0996 & AMO-892 & GACCTCGAGCAAAGAAATTGCTGGTGGTAATG & AMO-893 & GTTGAGCTCAGAGTCTGTTTTGGGTGTAG \\
\hline all1738 & AMO-895 & GTAGACCAAGTATGG & AMO-896 & GAATTCGACCACCAATTACTAC \\
\hline all3169 & AMO-897 & AAGCTTGGGGGTGACCTGCATCC & AMO-898 & TCTGAATTCACTGGCGCTGGCTAGAATC \\
\hline alr4808 & AMO-899 & GACTTGTGAAACCATTGC & AMO-900 & CCGAATTCAAACCAAACCCACAG \\
\hline alr0141 & AMO-901 & TAGAAGCTTCTTTGACAAGTCGGGG & AMO-902 & ACAGAATTCCACAGAGCGAAGAGC \\
\hline alr4738 & AMO-927 & GTGACTCGAGGTTATGAGTTATTGC & AMO-928 & CACCGAGCTCTTGTGCGCCCAAGCC \\
\hline alr3871 & AMO-937 & AGAGAGCTCCAGTTGGCACACTTG & AMO-938 & ACAAGGATCCGGCTGTAGTTGAAAGG \\
\hline all1682 & AMO-1794 & CAGAAGCTTGTACAAATACTAGTG & AMO-1795 & TTCСААТССССААТАТААААСАAC \\
\hline all4160 & AMO-1800 & TGAAAGCTTGGAATGTCACTCCCC & AMO-1801 & ACTGAGCTCCTGCCATTCACTTGC \\
\hline all3924 & AMO-1802 & TAAGTCTAGAGCTTACGACTTGGGGC & AMO-1803 & GCGAGAATTCCACCAATTACTGTTAG \\
\hline all1688 & AMO-1820 & CTCTCGTCGACCAGATTTCCCAAGAG & AMO-1821 & ATACGAATTCCTGTATCTTCTACTTG \\
\hline
\end{tabular}

were PCR products. Oligonucleotides and PCR products were UV cross-linked onto Corning GAPS II coated slides (Invitrogen). Each spot had a diameter of approximately $150 \mu \mathrm{m}$, and spots were aligned in an area of $1.5 \times 2.8 \mathrm{~cm}$.

For hybridization, total RNA was converted to an amino-allyl singlestranded cDNA and post-labelled with Cy5 or Cy3 fluorescent dyes (Amersham Biosciences) using the Superscript-II reverse transcriptase system and random primers (Invitrogen). Slides were pre-hybridized in $25 \%$ formamide, $5 \times$ SSC, $0.1 \%$ SDS and $2 \%$ BSA for $45 \mathrm{~min}$ at $42{ }^{\circ} \mathrm{C}$, then rinsed twice in distilled water and dried by centrifugation at $500 \mathrm{~g}$ for $3 \mathrm{~min}$. Hybridization was performed in a dark humid chamber at $42{ }^{\circ} \mathrm{C}$ for $16 \mathrm{~h}$ using a $4 \times$ hybridization solution (Amersham Biosciences). Slides were then washed with a pre-warmed solution of $2 \times \mathrm{SSC} / 0.2 \% \mathrm{SDS}$ at $55{ }^{\circ} \mathrm{C}$ followed by $1 \times \mathrm{SSC} / 0.2 \%$ SDS at $37{ }^{\circ} \mathrm{C}$ and finally with $0.1 \times \mathrm{SSC}$ at room temperature for $10 \mathrm{~min}$. Slides were then air-dried and subsequently scanned using an Affymetrix 428 Array scanner. Array images were generated in GPX and TIFF formats using GenePix-Pro software.

Normalization and statistical analysis of the raw microarray data were performed with GeneSpring Analysis Platform version 3.0 (Silicon Genetics) software. The median for each gene was determined from the median value for each replica spot, and each dataset for different RNA samples were normalized against the $r m p B$ gene from cells grown on ammonium. Genes were clustered into groups that were upregulated early $(0-4 \mathrm{~h})$, middle $(8-12 \mathrm{~h})$ and late (12-24 h) during heterocyst development. The middle genes were further narrowed to those that clustered with $90 \%$ correlation to hetC values to identify a set of genes that we would further analyse genetically.

Electron microscopy. Cultures were prepared for electron microscopy by collecting cyanobacterial filaments by centrifugation and resuspending the pellet in $2 \times$ BG-11, $2.5 \%$ acrolin, $2.5 \%$ glutaraldehyde and
$0.1 \%$ DMSO. Cells were fixed in a microwave for $2 \mathrm{~min}$ at $21{ }^{\circ} \mathrm{C}$ and $23 \mathrm{mmHg}$. The cells were washed three times in BG-11 medium and post-fixed in $3 \% \mathrm{~K}_{3} \mathrm{~F}(\mathrm{CN})_{6}$ overnight at $4{ }^{\circ} \mathrm{C}$. Fixed material was washed with distilled water four times at room temperature. Samples were embedded in $1 \%$ SeaKem low-gelling-temperature agarose. The samples were then dehydrated through a graded methanol series (two changes of 5 min each in 10,20,30, 40,50,60, 70, 80 and $90 \%$ methanol, and three changes of $10 \mathrm{~min}$ each in $100 \%$ methanol) and two $10 \mathrm{~min}$ incubations in propylene oxide. The samples were infiltrated with a $1: 1$ mixture of propylene oxide-Epon 812 for $4 \mathrm{~h}$ and then with a $1: 3$ mixture of propylene oxide-Epon 812 overnight with gentle agitation. The samples were incubated in Epon 812 under a vacuum at room temperature for $4 \mathrm{~h}$ and then embedded in BEEM capsules with fresh degassed Epon 812 overnight at $55{ }^{\circ} \mathrm{C}$. Thin sections were collected on Parlodion-carbon-coated copper grids and stained with $3 \%$ uranyl acetate for $30 \mathrm{~min}$ in a moist chamber. The sections were examined with a Siemens 101 electron microscope operated at $80 \mathrm{kV}$.

Light and fluorescence microscopy. Differential interference contrast (DIC) and fluorescence microscopy were performed on two microscope systems: a Zeiss Axioplan II microscope with a $40 \times$ objective and GFP-specific emission $(518 \pm 13 \mathrm{~nm})$ filter sets and a Hamamatsu 3 charge-coupled device (CCD) camera (C5810); and an Olympus IX70 inverted microscope with a $100 \times$ objective and Hamamatsu OrcaER C4742-95 CCD camera and Simple PCI software version 6.0 (Compix). A Piston GFP band-pass filter set (no. 41025; Chroma Technology) was used for fluorescence images with the IX70 to minimize background from autofluorescence. The images were minimally processed to improve contrast and brightness with Adobe Photoshop CS version 8.0.

Acetylene reduction assay. Wild-type Anabaena PCC 7120 and the conR mutant strain AMC1369 were first grown in $100 \mathrm{ml} \mathrm{BG-11} \mathrm{in}$ 
$250 \mathrm{ml}$ flasks under standard conditions to $\mathrm{OD}_{750} 0.4$. The cells were collected by centrifugation in $250 \mathrm{ml}$ conical bottles at room temperature, washed twice with $50 \mathrm{ml}$ water, resuspended in $3 \mathrm{ml}$ BG- $11_{0}$ and transferred to $10 \mathrm{ml}$ tubes that were sealed with a rubber serum stopper. One millilitre of air was replaced with acetylene, and the tube was mixed by inversion for $1 \mathrm{~min}$. The cells were incubated at $30{ }^{\circ} \mathrm{C}$ with standard illumination, and $0.1 \mathrm{ml}$ samples of gas were removed at $0,8,12,16$ and $24 \mathrm{~h}$ for analysis by gas chromatography with a 6-ft Porapak $\mathrm{N}$ column at $50{ }^{\circ} \mathrm{C}$.

\section{RESULTS}

\section{Identification and bioinformatics analysis of conR}

To identify genes that are potentially involved in the early stages of heterocyst development in Anabaena PCC 7120, we performed DNA microarray transcription profiling experiments of the wild-type to examine gene expression in the presence of ammonium and nitrate, and at different times after nitrogen step-down. From these data, we identified a set of genes that showed a pattern of expression similar to hetC (data not shown). The hetC gene is predicted to encode a bacterial $\mathrm{ABC}$ protein exporter and is upregulated 5-9 h after the onset of heterocyst differentiation (Khudyakov \& Wolk, 1997).

Fifteen candidate genes that were regulated similarly to het $C$ were inactivated to assess their role in heterocyst development. The following loci were inactivated by single recombination with suicide plasmids that each contained an internal fragment of the target gene: alr0141, all0187, alr0295, alr0996, all1682, all1688, all1738, all3169, all3290, alr3871, all3924, all4160, alr4738, alr4808 and alr4882. For the alr0141 and all3169 loci, no exconjugants were obtained. For the remaining loci, exconjugants were obtained and restreaked to allow segregation of mutant chromosomes, which is required because cyanobacteria contain multiple chromosome copies per cell ( $\mathrm{Hu}$ et al., 2007). With the exception of all0187, none of the other mutants exhibited a diazotrophic growth defect or obvious defects in heterocyst differentiation or pattern formation.

Inactivation of all0187 (Fig. 1) caused defective diazotrophic growth, among other defects described below. Concurrent with our work, a transposon mutant of all0187 was briefly described by Fan et al. (2006) who named the gene conR.

The conR gene product is predicted to contain an $\mathrm{N}$ terminal transmembrane region (residues 83-105) but lacks a predicted signal sequence. ConR is predicted to contain a LytR-CpsA-Psr domain (residues 174-323), which is found in a group of proteins that are involved in septation and cell-wall maintenance (Chatfield et al., 2005; Hübscher et al., 2008; Johnsborg \& Havarstein, 2009). These proteins have a short $\mathrm{N}$-terminal cytoplasmic domain and a transmembrane domain that together form a signal anchor which can be inserted into the cell membrane (Koskiniemi et al., 1998). The biochemical function of the LytR-CpsA-Psr domain is not yet known. The

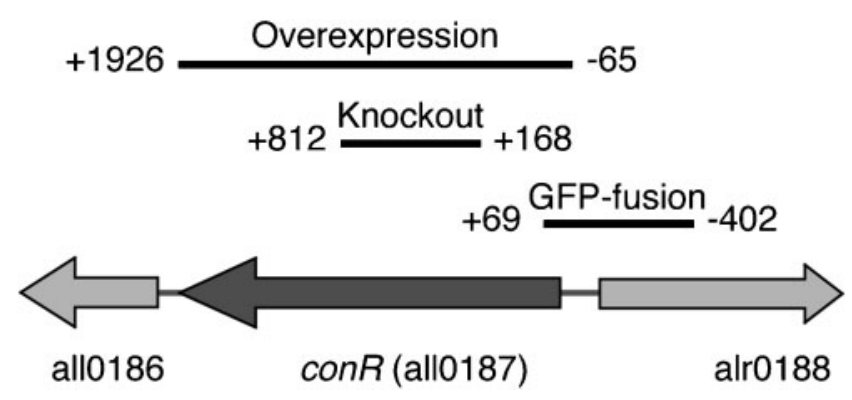

Fig. 1. Map of conR (all0187) on the Anabaena PCC 7120 chromosome and the DNA fragments used in this study for genetic experiments. Suicide plasmid pAM3438 contains an internal fragment of conR (knockout) and was used to inactivate conR by single homologous recombination into the chromosome. Plasmid pAM3448 contains the entire conR ORF (overexpression) under control of the $r b c L$ promoter and was used to overexpress conR. Plasmid pAM3450 contains the upstream region of con $R$ (GFP-fusion) fused to the gfpmut2 reporter gene. Numbering is relative to the first nucleotide of the conR ORF.

LytR-CpsA-Psr domain has been confused with the LytTR domain (previously also named LytR) that is found in a group of transcriptional regulators predicted to have DNAbinding properties (Nikolskaya \& Galperin, 2002). This confusion in gene names has led to the misannotation of the $\operatorname{con} R$ gene and its homologues in genomics databases, and, consequently by Fan et al. (2006), as being a transcriptional regulator. Our bioinformatics analysis of the Anabaena PCC 7120 genome identified two genes predicted to contain a LytR-CpsA-Psr domain, conR (all0187) and alr2479, and both genes are incorrectly annotated in public databases as transcriptional regulators.

\section{Characterization of a conR knockout mutant}

The conR gene was insertionally inactivated by single homologous recombination with a suicide plasmid that contained an internal fragment of the gene (Fig. 1). Southern blot and PCR analysis (data not shown) showed that no copies of the wild-type gene could be detected in the mutant strain grown under antibiotic selection. The phenotype of the resulting mutant strain, AMC1369, was analysed in medium with or without a source of combined nitrogen. In medium containing nitrate, the mutant cells grew noticeably slower than the wild-type grown under the same conditions.

Vegetative cells of the mutant strain appeared smaller and highly granular, and were partially defective for septum formation and cell division and, consequently, some cells appeared longer than normal (Fig. 2e and i). In medium without a source of combined nitrogen, the AMC1369 mutant filaments were able to form heterocysts with a fairly normal pattern along the filament, but were unable to grow diazotrophically (Fig. 2f). AMC1369 filaments transferred 
from BG-11 to BG- $11_{0}$ liquid media yellowed and died after 2-3 days. The vegetative cells had a somewhat more normal appearance after nitrogen step-down but still showed partially defective septum formation (Fig. 2j).

Time-lapse microscopy of mutant filaments after nitrogen step-down (see Supplementary Movie S1, available with the online version of this paper) revealed that differentiating cells elongated and often appeared to have defective septum formation with the neighbouring vegetative cell(s), resulting in abnormally long heterocysts that appeared partially open at their ends (Fig. 2d and h). Differentiating cells exceeded normal length (and continued to elongate) at around $9 \mathrm{~h}$ after nitrogen stepdown, a time when proheterocysts are not yet clearly morphologically distinguishable in the wild-type strain. After nitrogen step-down, if vegetative cells did not undergo division prior to differentiating into a heterocyst, then the septum formation defect was not obvious. After $24 \mathrm{~h}$, only a few regions of the filaments continued to grow; presumably, those regions had heterocysts that had produced functional junctions with their neighbouring vegetative cells.

The mutant phenotype described above was observed in several independent exconjugant clones. The conR mutant strain AMC1369 was complemented with shuttle plasmid pAM3448, which carries the conR gene expressed from the $r b c L$ promoter. The complemented strain had a wild-type phenotype, which shows that the inactivation of conR was responsible for all of the observed phenotypes. Overexpression of conR from pAM3448 in a wild-type background did not produce an abnormal phenotype in either nitrogen-containing or nitrogen-free medium (data not shown).

The conR mutant strain was unable to grow diazotrophically even though heterocysts were present. Therefore, we used electron microscopy to determine whether the heterocyst envelope layers were absent or altered (Fig. $2 \mathrm{~d}$ and $\mathrm{g}$ ). The electron micrographs showed that the glycolipid, polysaccharide, peptidoglycan and outer membrane layers of the heterocyst envelope in AMC1369 were all present, but that both vegetative cells and heterocysts often contained round inclusions of low electron density in the cytoplasm that were not present in the wild-type. These inclusions are presumably poly- $\beta$-hydroxybutyrate granules that accumulate because the filaments are limited for fixed nitrogen (Wu et al., 2001). Thin layer chromatography experiments showed that heterocyst glycolipids were present in the mutant strain (data not shown). Fan et al. (2006) had previously observed that a mutant strain with a transposon insertion in the all0187 locus could not grow diazotrophically but contained heterocyst glycolipids similar to the wild-type. They also showed that the junctions between vegetative cells and between vegetative

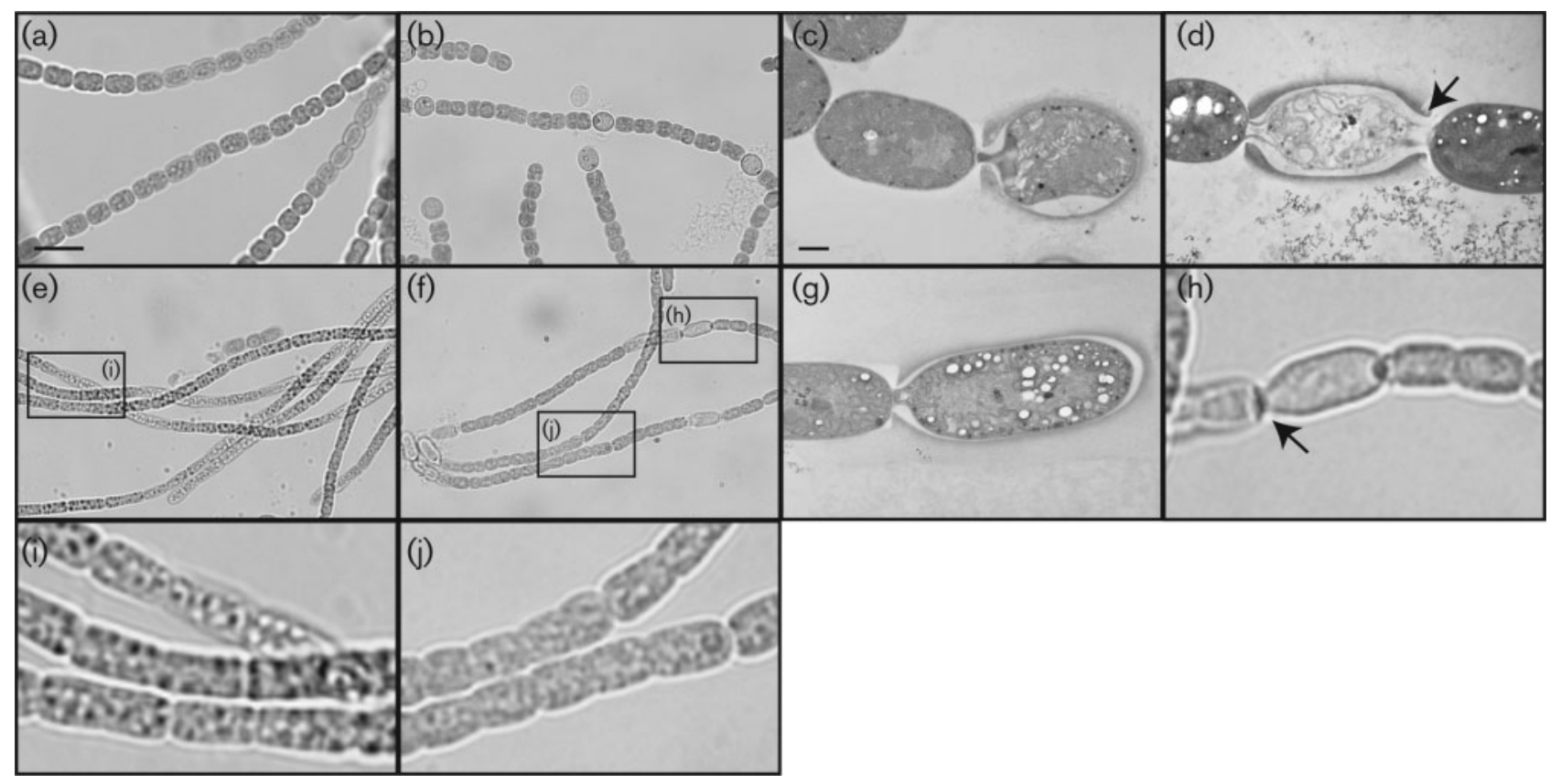

Fig. 2. conR mutant phenotype. The strain $A M C 1369$ is defective for both normal vegetative cell division and heterocyst morphogenesis. Anabaena PCC 7120 wild-type $(\mathrm{a}-\mathrm{c})$ and conR mutant AMC1369 $(\mathrm{d}-\mathrm{j})$ strains grown in nitrate-containing BG-11 medium ( $a, e)$ or nitrate-free BG-11。 medium ( $b-d, f-j)$. Bars, $10 \mu \mathrm{m}$ in the DIC micrograph (a) and $500 \mathrm{~nm}$ in the electron micrograph (c). Light micrographs ( $a, b$, e and f) are all the same magnification; and electron micrographs (c, $d$ and $g$ ) are all the same magnification. ( $h, j$ ) Boxed regions in ( $f$ ). (i) Boxed region in (e). Arrows indicate abnormal cell poles that appear open. 
cells and heterocysts were often partially defective (Fan et al., 2006).

\section{Expression of conR}

To validate the microarray data (not shown) for $\operatorname{con} R$ and confirm that expression of conR increases after nitrogen step-down, we performed a Northern RNA blot analysis on independently isolated RNA samples. Total RNA was extracted from wild-type Anabaena PCC 7120 and from the conR mutant strain AMC1369 at 0, 4, 8, 12 and $24 \mathrm{~h}$ after nitrogen step-down. Fig. 3 shows that conR transcripts could be weakly detected in uninduced filaments and increased from this basal level by $8 \mathrm{~h}$ after nitrogen stepdown, and continued to increase until $12 \mathrm{~h}$, but then returned to lower levels by $24 \mathrm{~h}$. The Northern blot showed

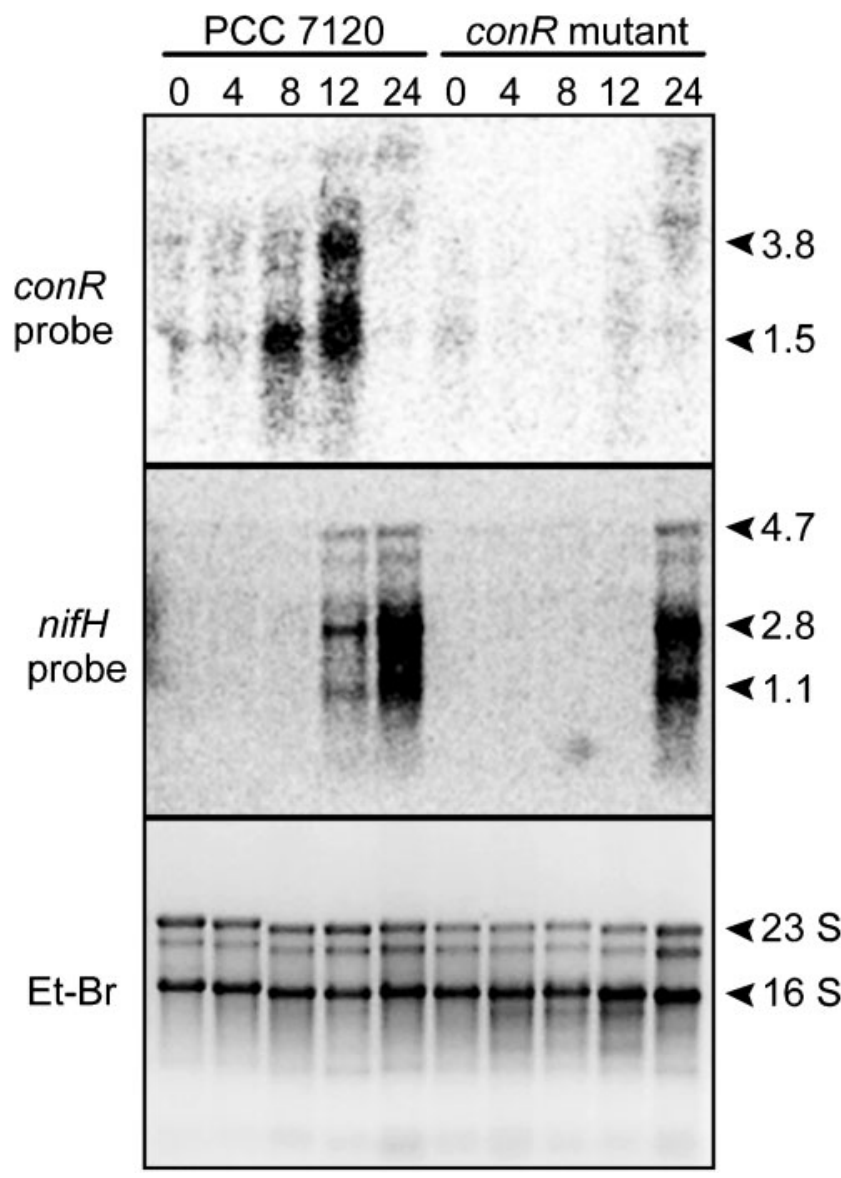

Fig. 3. Northern RNA blot analysis of conR and nifH genes in wildtype PCC 7120 and the conR mutant strain AMC1369 during heterocyst development. Lanes are labelled with the time after nitrogen step-down $(h)$. The lower panel is the ethidium bromidestained gel to show sample loading. The upper and middle panels show Northern RNA blots probed with radioactive probes for conR or nifH genes, respectively. For conR, 3.8 and $1.5 \mathrm{~kb}$ transcripts were detected, and for $\mathrm{nifH}$, three transcripts were detected at 4.7, 2.8 and $1.1 \mathrm{~kb}$. two relatively stable transcripts at 1.5 and $3.8 \mathrm{~kb}$, which would correspond to, respectively, conR alone and to transcripts containing conR, all0186 and all0185. RNA-seq data from total RNA samples obtained at $0,6,12$ and $21 \mathrm{~h}$ after nitrogen step-down were consistent with the microarray and Northern blot data, with RPKM [reads per kilobase of CDS (coding sequence) model per million mapped reads] values of $11.19,9.64,64.29$, and 32.11, respectively (B. Flaherty, unpublished data). The RNA-seq data indicated a major $5^{\prime}$ end for conR transcripts at -103 nt upstream of the first base of the ORF.

RNA-seq RPKM data for the other Anabaena PCC 7120 LytR-CpsA-Psr-domain gene, alr2479, showed RPKM values of $5.15,4.22,40.15$ and 14.52 , respectively. This expression pattern is similar to that of conR and suggests that $\operatorname{conR}$ and alr2479 might be involved in similar processes.

To determine if the increase in expression of conR takes place in differentiating cells, we constructed a $\mathrm{P}_{\text {conR }}-g f p$ reporter (Fig. 4). Time-lapse microscopy of the wild-type carrying the $\mathrm{P}_{\text {conR }}-g f p$ reporter on shuttle plasmid pAM3450 showed that after nitrogen step-down, GFP fluorescence increased in differentiating cells, but only after about $18 \mathrm{~h}$, and there was only a modest difference between vegetative cells and heterocysts. GFP fluorescence began to decrease in heterocysts after about $28 \mathrm{~h}$. GFP fluorescence from vegetative cells also increased following nitrogen step-down but remained at a lower level compared with heterocysts (Fig. 4).

\section{Nitrogen fixation in the conR mutant}

Because the conR mutant strain failed to grow diazotrophically, even though it had an apparently normal heterocyst envelope, we determined if the nifH gene was expressed at normal levels. Previous studies have shown that the nifHDK operon is strongly upregulated $12-24 \mathrm{~h}$ after heterocyst induction in the wild-type, depending on incubation conditions (Borthakur et al., 1990; Golden et al., 1991; Wei et al., 1994). Under our conditions, nifH expression in the wild-type began to increase by $12 \mathrm{~h}$ after nitrogen step-down (Fig. 3). In the conR mutant strain, nifH expression was nearly equivalent to the wild-type at $24 \mathrm{~h}$ after nitrogen step-down, but the expression was delayed such that no expression was evident at $12 \mathrm{~h}$. In these experiments, the timing of heterocyst morphogenesis assessed by light microscopy was similar to the wild-type and did not show any delay.

Because we observed significant expression of the nifH gene, acetylene reduction assays were used to determine if nitrogenase was active in the conR mutant strain. Even though the conR mutant cannot grow diazotrophically, nitrogenase activity in a $24 \mathrm{~h}$ period after nitrogen stepdown was $70 \%$ of the level produced by the wild-type. These results suggest that the diazotrophic growth defect is not due to the inability of the heterocysts to express the 


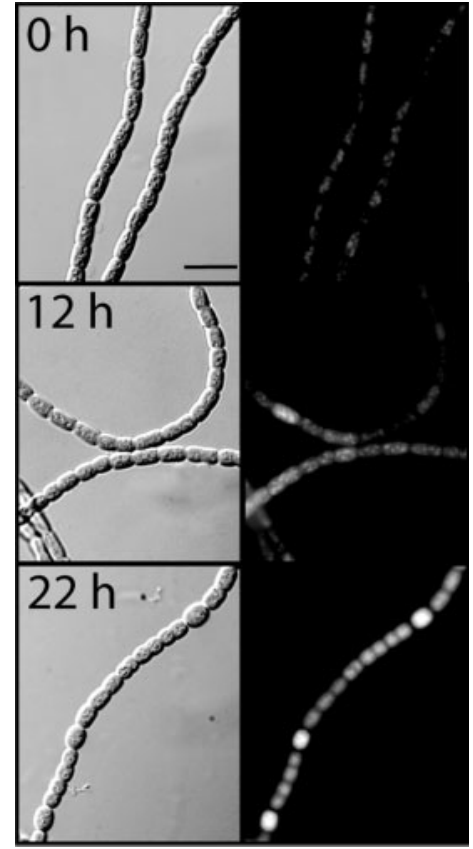

Fig. 4. $A P_{c o n R}-g f p$ reporter strain (AMC1370) showed increasing GFP fluorescence in differentiating cells after nitrogen step-down. DIC images of AMC1370 filaments (left) and corresponding GFP fluorescence images (right) of filaments 0,12 and $22 \mathrm{~h}$ after nitrogen step-down. Bar, $10 \mu \mathrm{m}$.

nitrogen fixation genes or to produce functional nitrogenase, but is instead due to an inability to supply fixed nitrogen to the neighbouring vegetative cells.

\section{DISCUSSION}

DNA microarray transcript profiling data showed that the Anabaena PCC 7120 conR (all0187) gene was expressed similarly to genes involved in the early stages of heterocyst development. In work done concurrently with our initial identification of $\operatorname{con} R$, a $\operatorname{con} R$ mutant was characterized by Fan and colleagues who had identified it in a transposon mutagenesis screen for mutants defective for diazotrophic growth (Fan et al., 2006). Our microarray experiments showed that the expression of conR was upregulated $8 \mathrm{~h}$ after nitrogen step-down. A heterocyst induction timecourse with a $\mathrm{P}_{c o n R}-g f p$ reporter strain showed upregulated expression at this same time and showed moderately higher expression in differentiating cells. The conR expression data suggest that the ConR product is produced in higher amounts after nitrogen step-down in both vegetative cells and differentiating heterocysts.

The conR gene was inactivated by single homologous recombination with an internal fragment carried on a suicide vector, and similar to the transposon mutant identified by Fan et al. (2006), the mutant could not grow diazotrophically and produced heterocysts with abnormal morphology and defective junctions with vegetative cells. Filaments of the conR mutant strain AMC1369 grown in nitrate-containing media also showed defects in cell division and septum formation of vegetative cells. After nitrogen step-down, the defect in septum formation between vegetative cells seemed less severe than for filaments grown with nitrate, which could be an indirect consequence of a general stress response or due to the slightly slowed growth caused by the transition to diazotrophic growth.

A bioinformatics screen for potential NtcA-regulated genes identified a putative NtcA binding site at position -60 relative to the start codon of conR (Su et al., 2005), which could be consistent with the upregulation of conR that occurs in differentiating heterocysts. However, RNA-seq data showed a major stable $5^{\prime}$ end at -103 ; if this is a transcription start site, then that would place the conR promoter within the upstream divergent ORF alr0188 and would indicate that the computationally identified NtcA binding site is not involved in the regulation of $\operatorname{con} R$.

The conR gene is predicted to encode a protein containing an $\mathrm{N}$-terminal transmembrane domain and a periplasmic LytR-CpsA-Psr domain. In Bacillus subtilis, a lytR mutant shows upregulation of the lytABC operon, which is involved in synthesis and maintenance of the cell wall; LytC is an $\mathrm{N}$-acetyl-muramoyl-L-alanine amidase (autolysin) involved in cleaving peptidoglycan (Lazarevic et al., 1992). Disruption of the lytR gene in Streptococcus pneumoniae results in misplacement of the septum (Johnsborg \& Havarstein, 2009). In many bacteria, the peptidoglycan cell wall is cleaved by multiple hydrolases, including amidases, which remove peptide side chains from the carbohydrate polymer. Peptidoglycan hydrolases, autolysins, are thought to be essential for separating daughter cells after cell division is concluded, and their absence causes incomplete septal invagination (Priyadarshini et al., 2007). Based on the conR mutant phenotype, it is possible that the set of peptidoglycan hydrolases involved in septation between vegetative cells, or their regulation, are at least partially different from those involved in septation between differentiating heterocysts and vegetative cells. Autolysins may also be required for modification of the heterocyst peptidoglycan to facilitate transport and assembly of the outer envelope layers, and autolysin activity and hydrostatic pressure may explain the often larger and rounder shape of heterocysts.

In Anabaena PCC 7120, the autolysin gene howA is required for normal heterocyst maturation (Zhu et al., 2001). We hypothesized that the abnormal cell division of the conR mutant might be caused by altered expression of $h c w A$. However, we did not detect a change in howA mRNA levels in the conR mutant (data not shown). Alternatively, the enzymic activity or localization of HcwA or other autolysins may be altered in the conR mutant.

In many cases, the inability of an Anabaena PCC 7120 mutant to grow diazotrophically may be caused by a defect 
that compromises the integrity of the envelope layers, allowing more oxygen to enter the heterocysts and inactivate nitrogenase. However, the conR mutant formed heterocysts with apparently normal polysaccharide and glycolipid layers. We asked if the incomplete constriction of the septum between heterocyst and vegetative cells might expose the intracellular environment of the heterocysts to oxygen and, thus, cause a decrease in the expression or activity of nitrogenase. Northern blot analysis showed that nifH expression in the conR mutant was upregulated after nitrogen step-down, but with a substantial delay compared with the wild-type. Although morphological heterocyst development observed by light microscopy was not delayed in the mutant strain, the delay in nifH expression may have been caused by delayed establishment of a micro-oxic environment due to delayed or partially defective septum formation or deposition of the envelope layers.

Unexpectedly, the conR mutant retained nitrogenase activity at $70 \%$ of wild-type levels, and this amount of activity should be sufficient to sustain diazotrophic growth (Valladares et al., 2007), although possibly at a slower rate. Inactivation of the heterocyst-specific gene $f d x H$ reduced nitrogenase activity to less than $50 \%$, but still allowed slow diazotrophic growth (Masepohl et al., 1997). However, conR mutant filaments completely stopped growing after a few days in medium without a source of combined nitrogen, and the cells yellowed and died. Therefore, the vegetative cells must not be receiving nitrogen even though at least some of the heterocysts of the conR mutant are capable of creating a micro-oxic environment that supports significant nitrogenase activity. These data show that the diazotrophic growth defect is not caused simply by defective nitrogen fixation, but may involve defective delivery of fixed nitrogen from heterocysts to neighbouring vegetative cells. Recent findings show that there is cytoplasm-to-cytoplasm movement of the small fluorophore calcein in Anabaena PCC 7120, which indicates the existence of non-specific intercellular channels that allow metabolite exchange between cells of the filament (Mullineaux et al., 2008). In the conR mutant, defective septum formation and closure could interfere with the formation of these channels at the junction between heterocysts and vegetative cells and, thus, prevent normal metabolite exchange.

\section{ACKNOWLEDGEMENTS}

We thank Britt Flaherty for her unpublished RNA-seq data. This work was supported by National Science Foundation Grant 0925126.

\section{REFERENCES}

Aldea, M. R., Kumar, K. \& Golden, J. W. (2008). Heterocyst development and pattern formation. In Chemical Communication Among Bacteria, pp. 75-90. Edited by S. C. Winans \& B. L. Bassler. Washington, DC: American Society for Microbiology.

Awai, K., Lechno-Yossef, S. \& Wolk, C. P. (2009). Heterocyst Envelope Glycolipids. In Lipids in Photosynthesis: Essential and
Regulatory Functions, pp. 179-202. Edited by H. Wada \& N. Murata. New York: Springer.

Borthakur, D., Basche, M., Buikema, W. J., Borthakur, P. B. \& Haselkorn, R. (1990). Expression, nucleotide sequence and mutational analysis of two open reading frames in the nif gene region of Anabaena sp. strain PCC7120. Mol Gen Genet 221, 227-234.

Borthakur, P. B., Orozco, C. C., Young-Robbins, S. S., Haselkorn, R. \& Callahan, S. M. (2005). Inactivation of pat $S$ and het $N$ causes lethal levels of heterocyst differentiation in the filamentous cyanobacterium Anabaena sp. PCC 7120. Mol Microbiol 57, 111-123.

Chatfield, C. H., Koo, H. \& Quivey, R. G., Jr (2005). The putative autolysin regulator LytR in Streptococcus mutans plays a role in cell division and is growth-phase regulated. Microbiology 151, 625-631.

Elhai, J., Vepritskiy, A., Muro-Pastor, A. M., Flores, E. \& Wolk, C. P. (1997). Reduction of conjugal transfer efficiency by three restriction activities of Anabaena sp. strain PCC 7120. J Bacteriol 179, 1998-2005.

Fan, Q., Huang, G., Lechno-Yossef, S., Wolk, C. P., Kaneko, T. \& Tabata, S. (2005). Clustered genes required for synthesis and deposition of envelope glycolipids in Anabaena sp. strain PCC 7120. Mol Microbiol 58, 227-243.

Fan, Q., Lechno-Yossef, S., Ehira, S., Kaneko, T., Ohmori, M., Sato, N., Tabata, S. \& Wolk, C. P. (2006). Signal transduction genes required for heterocyst maturation in Anabaena sp. strain PCC 7120. J Bacteriol 188, 6688-6693.

Flores, E. \& Herrero, A. (2010). Compartmentalized function through cell differentiation in filamentous cyanobacteria. Nat Rev Microbiol 8, 39-50.

Golden, J. W., Whorff, L. L. \& Wiest, D. R. (1991). Independent regulation of nifHDK operon transcription and DNA rearrangement during heterocyst differentiation in the cyanobacterium Anabaena sp. strain PCC 7120. J Bacteriol 173, 7098-7105.

Herrero, A., Muro-Pastor, A. M., Valladares, A. \& Flores, E. (2004). Cellular differentiation and the NtcA transcription factor in filamentous cyanobacteria. FEMS Microbiol Rev 28, 469-487.

Hu, B., Yang, G., Zhao, W., Zhang, Y. \& Zhao, J. (2007). MreB is important for cell shape but not for chromosome segregation of the filamentous cyanobacterium Anabaena sp. PCC 7120. Mol Microbiol 63, 1640-1652.

Huang, X., Dong, Y. \& Zhao, J. (2004). HetR homodimer is a DNAbinding protein required for heterocyst differentiation, and the DNAbinding activity is inhibited by PatS. Proc Natl Acad Sci U S A 101, 4848-4853.

Huang, G., Fan, Q., Lechno-Yossef, S., Wojciuch, E., Wolk, C. P., Kaneko, T. \& Tabata, S. (2005). Clustered genes required for the synthesis of heterocyst envelope polysaccharide in Anabaena sp. strain PCC 7120. J Bacteriol 187, 1114-1123.

Hübscher, J., Luthy, L., Berger-Bachi, B. \& Stutzmann Meier, P. (2008). Phylogenetic distribution and membrane topology of the LytR-CpsA-Psr protein family. BMC Genomics 9, 617.

Johnsborg, O. \& Havarstein, L. S. (2009). Pneumococcal LytR, a protein from the LytR-CpsA-Psr family, is essential for normal septum formation in Streptococcus pneumoniae. J Bacteriol 191, 5859-5864.

Khudyakov, I. Y. \& Golden, J. W. (2001). Identification and inactivation of three group 2 sigma factor genes in Anabaena sp. strain PCC 7120. J Bacteriol 183, 6667-6675.

Khudyakov, I. \& Wolk, C. P. (1997). hetC, a gene coding for a protein similar to bacterial ABC protein exporters, is involved in early regulation of heterocyst differentiation in Anabaena sp. strain PCC 7120. J Bacteriol 179, 6971-6978.

Koskiniemi, S., Sellin, M. \& Norgren, M. (1998). Identification of two genes, $\operatorname{cps} X$ and $\operatorname{cps} Y$, with putative regulatory function on capsule 
expression in group B streptococci. FEMS Immunol Med Microbiol 21, 159-168.

Kumar, K., Mella-Herrera, R. A. \& Golden, J. W. (2010). Cyanobacterial heterocysts. Cold Spring Harb Perspect Biol 2, a000315.

Lazarevic, V., Margot, P., Soldo, B. \& Karamata, D. (1992). Sequencing and analysis of the Bacillus subtilis lytRABC divergon: a regulatory unit encompassing the structural genes of the $N$-acetylmuramoyl-L-alanine amidase and its modifier. J Gen Microbiol 138, 1949-1961.

Lechno-Yossef, S., Fan, Q., Ehira, S., Sato, N. \& Wolk, C. P. (2006). Mutations in four regulatory genes have interrelated effects on heterocyst maturation in Anabaena sp. strain PCC 7120. J Bacteriol 188, 7387-7395.

Liu, D. \& Golden, J. W. (2002). hetL overexpression stimulates heterocyst formation in Anabaena sp. strain PCC 7120. J Bacteriol 184, 6873-6881.

Mariscal, V., Herrero, A. \& Flores, E. (2007). Continuous periplasm in a filamentous, heterocyst-forming cyanobacterium. Mol Microbiol 65, 1139-1145.

Masepohl, B., Scholisch, K., Gorlitz, K., Kutzki, C. \& Bohme, H. (1997). The heterocyst-specific $f d x H$ gene product of the cyanobacterium Anabaena sp. PCC 7120 is important but not essential for nitrogen fixation. Mol Gen Genet 253, 770-776.

Mullineaux, C. W., Mariscal, V., Nenninger, A., Khanum, H., Herrero, A., Flores, E. \& Adams, D. G. (2008). Mechanism of intercellular molecular exchange in heterocyst-forming cyanobacteria. EMBO J 27, 1299-1308.

Muro-Pastor, A. M., Valladares, A., Flores, E. \& Herrero, A. (2002). Mutual dependence of the expression of the cell differentiation regulatory protein HetR and the global nitrogen regulator NtcA during heterocyst development. Mol Microbiol 44, 1377-1385.

Muro-Pastor, A. M., Flores, E. \& Herrero, A. (2009). NtcA-regulated heterocyst differentiation genes hetC and $\operatorname{dev} B$ from Anabaena sp. strain PCC 7120 exhibit a similar tandem promoter arrangement. J Bacteriol 191, 5765-5774.

Nikolskaya, A. N. \& Galperin, M. Y. (2002). A novel type of conserved DNA-binding domain in the transcriptional regulators of the AlgR/ AgrA/LytR family. Nucleic Acids Res 30, 2453-2459.

Popa, R., Weber, P. K., Pett-Ridge, J., Finzi, J. A., Fallon, S. J., Hutcheon, I. D., Nealson, K. H. \& Capone, D. G. (2007). Carbon and nitrogen fixation and metabolite exchange in and between individual cells of Anabaena oscillarioides. ISME J 1, 354-360.

Priyadarshini, R., de Pedro, M. A. \& Young, K. D. (2007). Role of peptidoglycan amidases in the development and morphology of the division septum in Escherichia coli. J Bacteriol 189, 5334-5347.

Risser, D. D. \& Callahan, S. M. (2009). Genetic and cytological evidence that heterocyst patterning is regulated by inhibitor gradients that promote activator decay. Proc Natl Acad Sci U S A 106, 1988419888.

Sambrook, J. \& Russell, D. W. (2006). Northern Hybridization. Cold Spring Harb Protoc. doi:10.1101/pdb.prot3723.

Su, Z., Olman, V., Mao, F. \& Xu, Y. (2005). Comparative genomics analysis of NtcA regulons in cyanobacteria: regulation of nitrogen assimilation and its coupling to photosynthesis. Nucleic Acids Res 33, 5156-5171.

Valladares, A., Maldener, I., Muro-Pastor, A. M., Flores, E. \& Herrero, A. (2007). Heterocyst development and diazotrophic metabolism in terminal respiratory oxidases mutants of the cyanobacterium Anabaena sp. strain PCC 7120. J Bacteriol 189, 44254430.

Wang, Y., Lechno-Yossef, S., Gong, Y., Fan, Q., Wolk, C. P. \& Xu, X. (2007). Predicted glycosyl transferase genes located outside the HEP island are required for formation of heterocyst envelope polysaccharide in Anabaena sp. strain PCC 7120. J Bacteriol 189, 5372-5378.

Waterbury, J. B. \& Willey, J. M. (1988). Isolation and growth of marine planktonic cyanobacteria. Methods Enzymol 167, 100-105.

Wei, T. F., Ramasubramanian, T. S. \& Golden, J. W. (1994). Anabaena sp. strain PCC $7120 n t c A$ gene required for growth on nitrate and heterocyst development. J Bacteriol 176, 4473-4482.

Wu, G. F., Wu, Q. Y. \& Shen, Z. Y. (2001). Accumulation of poly- $\beta$ hydroxybutyrate in cyanobacterium Synechocystis sp. PCC6803. Bioresour Technol 76, 85-90.

Wu, X., Lee, D. W., Mella, R. A. \& Golden, J. W. (2007). The Anabaena sp. strain PCC 7120 asr1734 gene encodes a negative regulator of heterocyst development. Mol Microbiol 64, 782-794.

Yoon, H. S. \& Golden, J. W. (1998). Heterocyst pattern formation controlled by a diffusible peptide. Science 282, 935-938.

Yoon, H. S. \& Golden, J. W. (2001). PatS and products of nitrogen fixation control heterocyst pattern. J Bacteriol 183, 2605-2613.

Zhang, C. C., Laurent, S., Sakr, S., Peng, L. \& Bedu, S. (2006). Heterocyst differentiation and pattern formation in cyanobacteria: a chorus of signals. Mol Microbiol 59, 367-375.

Zhang, L. C., Chen, Y. F., Chen, W. L. \& Zhang, C. C. (2008). Existence of periplasmic barriers preventing green fluorescent protein diffusion from cell to cell in the cyanobacterium Anabaena sp. strain PCC 7120. Mol Microbiol 70, 814-823.

Zhu, J., Jager, K., Black, T., Zarka, K., Koksharova, O. \& Wolk, C. P. (2001). HcwA, an autolysin, is required for heterocyst maturation in Anabaena sp. strain PCC 7120. J Bacteriol 183, 6841-6851.

Edited by: C.-C. Zhang 